Supporting Information

\title{
Energy transfer from a fluorescent hydrogel to a hosted fluorophore.
}

Marco Montalti ${ }^{*}$, Luisa Stella Dolci $^{a}$, Luca Prodi $^{a}$, Nelsi Zaccheroni ${ }^{a}$, Marc C. A. Stuart $^{b}$, Kjeld J. C. van Bommel ${ }^{b}$, Arianna Friggeri ${ }^{b}$

a) Dipartimento di Chimica “G. Ciamician” Università degli Studi di Bologna, Via Selmi 2, 40126 Bologna (Italy)

b) Biomade Technology Foundation Nijenborgh 4, 9747 AG Groningen (The Netherlands) Fax: (+31) 503634429

marco.montalti2@unibo.it,friggeri@biomade.nl

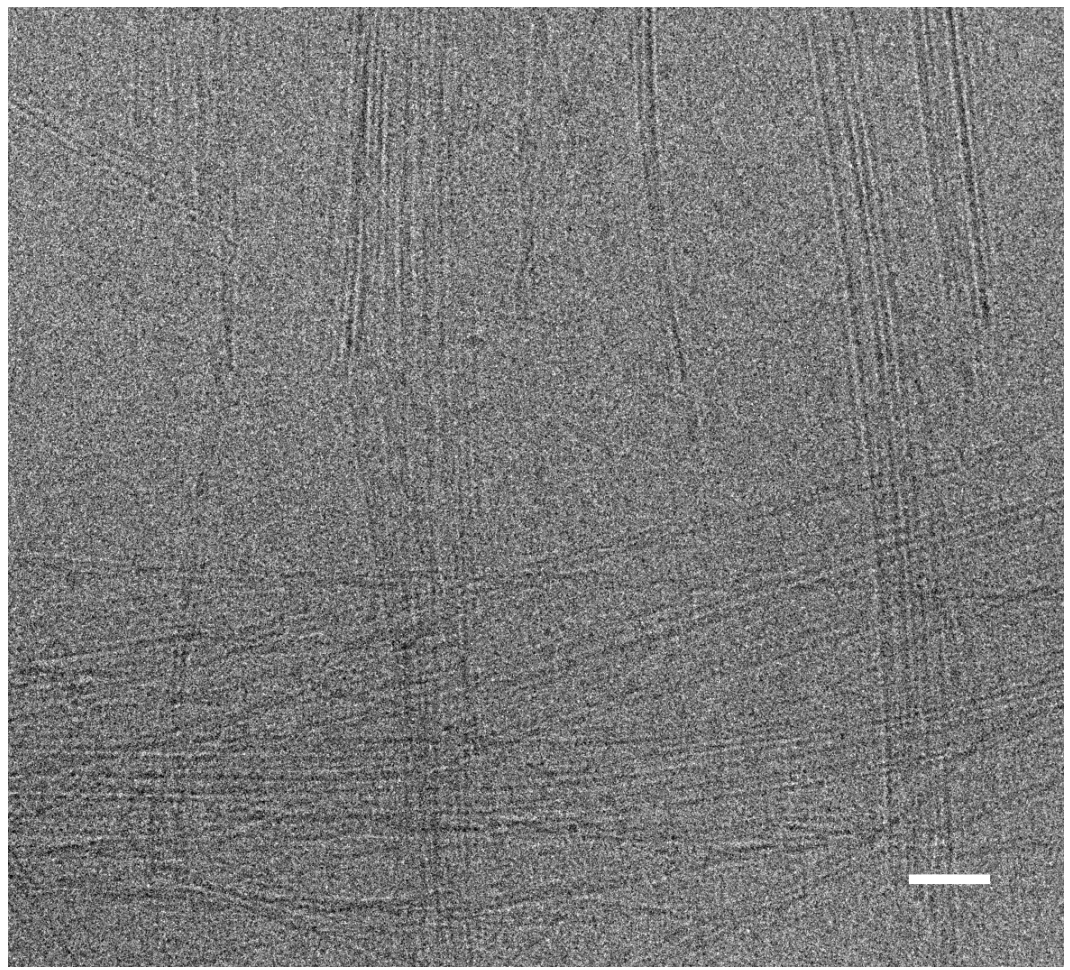

Figure 1. Cryo-TEM image of a gel of $\mathbf{1}\left(2.4 \times 10^{-3} \mathrm{M}\right)$ and PDNS $\left(8.0 \times 10^{-5} \mathrm{M}\right)$ in $9: 1=\mathrm{H}_{2} \mathrm{O}$ :DMSO (scale bar $=100 \mathrm{~nm})$. 


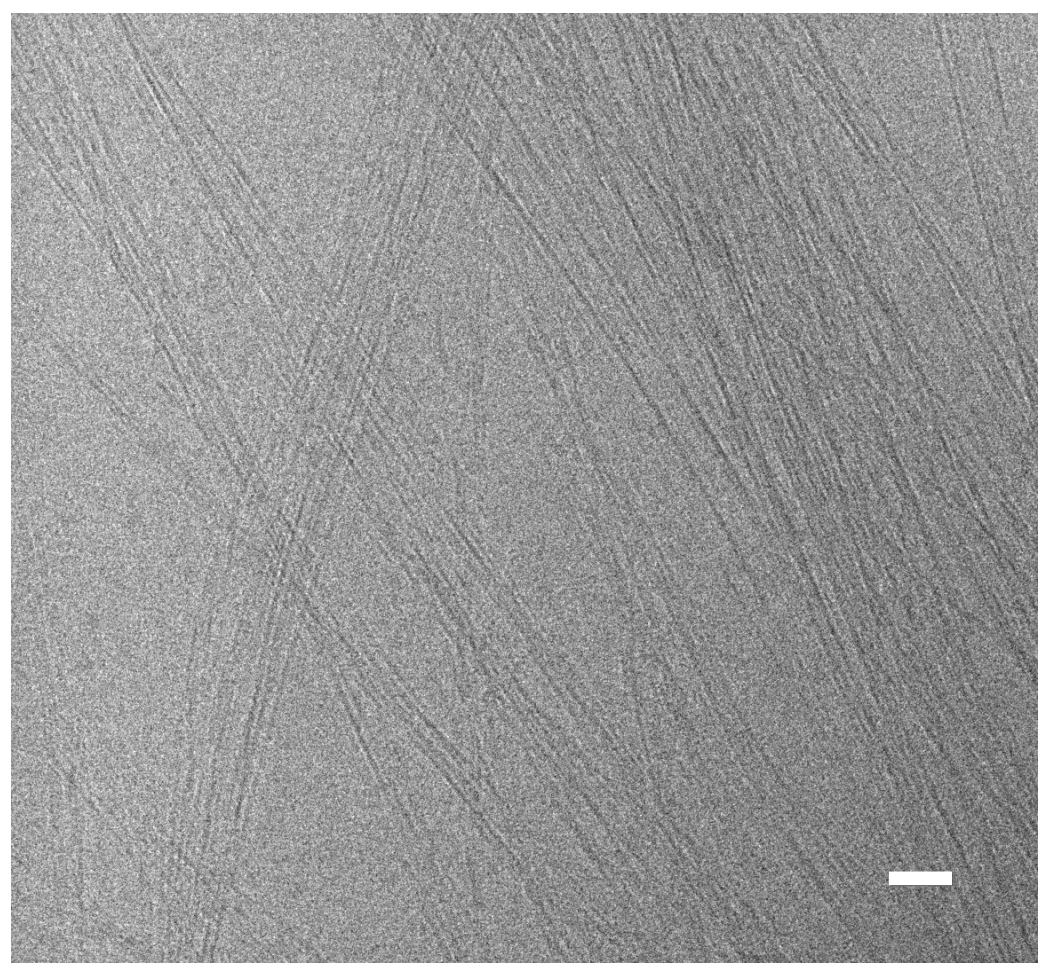

Figure 2. Cryo-TEM image of a gel of $\mathbf{1}\left(2.4 \times 10^{-3} \mathrm{M}\right)$ and PDNS $\left(4.0 \times 10^{-4} \mathrm{M}\right)$ in $9: 1=\mathrm{H}_{2} \mathrm{O}$ :DMSO $($ scale bar $=100 \mathrm{~nm})$. 